\title{
On the heterogeneous nucleation of mesospheric ice on meteoric smoke particles: Microphysical modeling
}

\author{
Heiner Asmus ${ }^{\mathrm{a}, *}$, Henrike Wilms ${ }^{\mathrm{b}}$, Boris Strelnikov ${ }^{\mathrm{a}}$, Markus Rapp ${ }^{\mathrm{b}, \mathrm{c}}$ \\ a Leibniz-Institute of Atmospheric Physics, Kühlungsborn, Germany \\ ${ }^{\mathrm{b}}$ Deutsches Zentrum für Luft- und Raumfahrt, Institut für Physik der Atmosphäre, Oberpfaffenhofen, Germany \\ ' Meteorologisches Institut München, Ludwig-Maximilians-Universität München, Munich, Germany
}

\section{A R T I C L E I N F O}

\section{Article history:}

Received 7 October 2013

Received in revised form

16 February 2014

Accepted 24 March 2014

Available online 24 April 2014

Keywords:

Mesospheric ice particles

NLC

Nucleation

Meteor smoke particles

\begin{abstract}
A B S T R A C T
Meteor smoke particles (MSP), which are thought to be the nucleation germs for mesospheric ice, are currently discussed to consist of highly absorbing materials such as magnesiowüstite, hematite or magnesium-iron-silicates and may therefore be warmer than the ambient atmosphere. In order to quantify the temperature difference between MSP and the atmosphere we developed a model to calculate the MSP equilibrium temperature in radiational and collisional balance. The temperature difference between MSP and the surrounding atmosphere strongly depends on the composition of the MSP, especially on the relative iron content, where a higher iron content leads to warmer MSP. We then derive an expression of the nucleation rate of mesospheric ice particles which explicitly accounts for this temperature difference. We find that the nucleation rate is strongly reduced by several orders of magnitude if the germ temperature is increased by only a few Kelvin. Implementing this nucleation rate depending on the germ temperature into CARMA, the Community Aerosol and Radiation Model for Atmospheres, we find that fewer but larger ice particles are formed compared to a reference scenario with no temperature difference between MSP and ambient atmosphere. This may indicate that iron-rich MSP are not ideal ice nuclei and that either other MSP-types or other nucleation pathways (e.g. wave induced heterogeneous nucleation or even homogeneous nucleation) are responsible for ice formation at the mesopause.
\end{abstract}

(c) 2014 Elsevier Ltd. All rights reserved.

\section{Introduction}

The summer polar mesopause region is known for the coldest temperatures on Earth ( $\sim 130 \mathrm{~K}$ Lübken and et al., 1990), low density and also as a part of the D- and lower E-region of the ionosphere. In combination with meteor smoke particles formed by re-condensing material of ablating meteoroids (Hunten et al., 1980) and neutral air dynamics some fascinating and scientifically interesting phenomena occur. These are, for example strong radar echoes, the so-called polar mesosphere summer echoes (PMSE) (Czechowsky et al., 1979; Ecklund and Balsley, 1981; Hoppe et al., 1988; Rottger et al., 1988) and the visible noctilucent clouds (NLC e.g., Jesse, 1896; Thomas, 1991). Both phenomena are closely related to the existence of ice particles in the mesosphere (e.g., Hervig et al., 2001, 2011; Rapp and Lübken, 2004). Even more than a century after their discovery the nucleation of these ice particles is still an ongoing topic in the current middle atmosphere

\footnotetext{
* Corresponding author.

E-mail address: asmus@iap-kborn.de (H. Asmus).
}

research. It has been assumed by most earlier investigations that mesospheric ice particles form on the meteor smoke particles (MSP) by heterogeneous nucleation, although other nucleation mechanisms such as homogeneous nucleation (Murray and Jensen, 2010) or ion induced nucleation might also be possible (Witt, 1969; Gumbel, 2003). While the composition of MSP has still not been experimentally determined there are indications from lab experiments and satellite extinction measurements that meteor smoke particles are believed to consist of olivine $\left(\mathrm{Mg}_{1.9} \mathrm{Fe}_{0.1} \mathrm{SiO}_{4}\right)$, hematite $\left(\mathrm{Fe}_{2} \mathrm{O}_{3}\right)$, different magnesium-ironsilicates $\left(\mathrm{Mg}_{x} \mathrm{Fe}_{1-\chi} \mathrm{SiO}_{3}\right)$ (Saunders et al., 2010) or wüstite (FeO) and magnesiowüstite $\left(\mathrm{Mg}_{x} \mathrm{Fe}_{1-x} \mathrm{O}\right)$ (Hervig et al., 2012). It is an obvious question how these different compositions influence the nucleation of mesospheric ice and which materials are more appropriate as nucleation germs or which can be excluded. Besides different surface properties the potential MSP materials differ in their radiative absorption coefficients, which leads to a material dependent MSP temperature. The current study seeks to quantify the abovementioned temperature difference between MSP and the ambient atmosphere and corresponding consequences for ice particle nucleation rates and polar mesospheric cloud (PMC) 
properties. In Section 2 we describe the model to determine the MSP equilibrium temperature as well as the equilibrium temperature of ice-smoke mixtures (i.e., "dirty ice”). In Section 3, we derive an expression for an MSP-temperature dependent nucleation rate which is followed by Section 4 in which results from such calculations are presented. Section 5 then finally demonstrates the effect of such modified nucleation rates on PMC-evolution using a full microphysical PMC-model. These results are discussed in Section 6 and our main conclusions are summarized in Section 7.

\section{Equilibrium temperatures of MSP and dirty ice}

\subsection{Case 1: pure MSP}

For the calculation of the equilibrium temperature of a spherical particle we assume that there are two power sources and two power sinks like former calculations from Fiocco et al. (1975), Eidhammer and Havnes (2001) and Espy and Jutt (2002). The balance between sources and sinks determines the equilibrium state of the particle. On one hand the radiation $P_{\text {sol }}$ in the visible and ultra violet range of the sun and the terrestrial radiation $P_{t e r}$ in the infrared range are the power sources. On the other hand infrared radiation of the particle $P_{\text {rad }}$ and collisions with air molecules $P_{c o l}$ are the sinks of power. Further heating due to latent heat transfer of condensing water vapor will be neglected in this model. For steady state conditions all contributions to the power budget can be expressed by the following balance equation:

$P_{\text {sol }}+P_{\text {ter }}-P_{\text {rad }}-P_{\text {col }}=0$.

The first term $P_{\text {sol }}$ of the balance equation (1) is defined as follows:

$P_{\text {sol }}=\pi r^{2} \epsilon(1+2 A \cos \chi) \int_{0}^{\infty} Q_{a b s}(\lambda, r, n(\lambda)) F_{\lambda}\left(T_{\odot}\right) \mathrm{d} \lambda$,

where $r$ is the particle radius and $\epsilon=\left(R_{\odot} / R_{0}\right)^{2}$ with the sun radius $R_{\odot}$ and the sun-earth distance $R_{0}$ is the solar dilution factor which accounts for the small solid angle occupied by the sun. The factor $1+2 A \cos \chi$ accounts for the direct radiation of the sun and the reflected radiation by the earth surface with albedo $A$ at solar zenith angle $\chi$. $Q_{a b s}$ is the absorption efficiency, $T_{\odot}$ the sun surface temperature and $F_{\lambda}\left(T_{\odot}\right)$ is the Planck formula for black body radiation

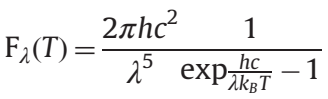

where $c$ is the speed of light, $h$ the Planck constant, $\lambda$ the wavelength, $k_{B}$ the Boltzmann constant and $T$ the surface temperature of the radiating body. The absorption efficiency $Q_{a b s}$ weights the radiation function and depends on the radius and optical properties of the particle. $Q_{a b s}$ is calculated from the extinction and scattering efficiencies $Q_{e x t}$ and $Q_{a b s}$

$Q_{a b s}=Q_{e x t}-Q_{s c a}$

determined by the Mie scattering code bhmie of Bohren and Huffman (1983). Meinen et al. (2012) showed for the example of hematite $\left(\mathrm{Fe}_{2} \mathrm{O}_{3}\right)$ that the bulk optical properties are still applicable down to particle diameters of $\sim 2-3 \mathrm{~nm}$. They found a good agreement between the experimentally determined extinction cross sections and those calculated by Mie theory.

The second term $P_{\text {ter }}$ in the balance equation describes the particle heating by upwelling infrared radiation and is defined as

$P_{\text {ter }}=\pi r^{2} \int_{0}^{\infty} Q_{a b s}(\lambda, r, n(\lambda)) F_{\lambda}\left(T_{E}\right) \mathrm{d} \lambda$.

The earth surface temperature $T_{E}$ is assumed to be the temperature of the warm stratopause.
The particle itself radiates with its surface temperature $T_{P}$ in the infrared. This power loss $P_{\text {rad }}$ can be described as

$P_{\text {rad }}=4 \pi r^{2} \int_{0}^{\infty} Q_{a b s}(\lambda, r, n(\lambda)) F_{\lambda}\left(T_{P}\right) \mathrm{d} \lambda$

where we assume that the aerosols radiate homogeneously in all directions.

The collision between the particle and the air molecules can be an additional power loss term if the air is colder than the particle. Otherwise the particle will be warmed by the collisions with the ambient gas molecules. In free molecular flow energy is transferred by collisions from a unit area with a rate $\Delta \Phi^{(E)}$. The expression of $\Delta \Phi^{(E)}$ was taken from Gombosi (1994) and was also used in the calculations of Espy and Jutt (2002). We neglect the particle fall velocity and the horizontal winds since we assume that the MSP are moving with the background wind. With this assumption the original equation of Gombosi (1994) reduces to

$\Delta \Phi^{(E)}=\frac{\alpha}{4} n_{\text {gas }} \bar{v} k_{b} \frac{\gamma+1}{2(\gamma-1)}\left(T_{P}-T_{A}\right)$.

The collisional energy transfer rate depends linearly on the thermal accommodation coefficient $\alpha$ which describes how efficient thermal energy is transferred between two bodies. $T_{P}-T_{A}$ is the temperature difference between the particle and the surrounding atmosphere. $n_{\text {gas }}$ is the surrounding gas number density with its mean thermal velocity $\bar{\nu} . \gamma$ is the heat capacity ratio. The collision power $P_{c o l}$ is obtained by integrating $\Delta \Phi^{(E)}$ over the aerosol surface. The particles are assumed to be spheres hence integration over the surface yields $4 \pi r^{2}$ :

$P_{\text {col }}=4 \pi r^{2} \Delta \Phi^{(E)}\left(T_{A}, T_{P}\right)$.

The particle temperature can now be derived from thermal equilibrium conditions described in Eq. (1). The power contributions of $P_{\text {rad }}$ and $P_{\text {col }}$ both depend on the particle temperature $T_{P}$, whereas $P_{\text {sol }}$ and $P_{\text {ter }}$ do not depend on $T_{P}$. However, $P_{\text {rad }}$ is a nontrivial function of $T_{P}$ so that a closed expression for $T_{P}$ cannot be found. We therefore apply an iterative scheme, where the particle temperature of the previous step $i-1$ is used in the term of $P_{\text {rad }}\left(T_{P}^{i-1}\right)$ to calculate $T_{P}^{i}$ in the following manner:

$T_{P}^{i}=T_{A}-\frac{P_{\text {rad }}\left(T_{P}^{i-1}\right)-P_{\text {sol }}-P_{\text {ter }}}{\alpha \pi r^{2} n_{\text {gas }} k_{b} \bar{v} \frac{\gamma+1}{2(\gamma-1)}}$.

In the initial step the particle temperature is equal to the ambient atmospheric temperature $\left(T_{P}^{0}=T_{A}\right)$. The iteration is terminated when $T_{P}$ reaches an asymptotic value, i.e. $\left|T_{P}^{i}-T_{P}^{i-1}\right|<10^{-3} \mathrm{~K}$.

The absorption efficiency $Q_{a b s}$ scales with $r$ in the Rayleigh limit $r \ll \lambda$ which is fulfilled for MSP in the relevant wavelength range. All radiative power terms therefore scale with $r^{3}$, whereas the collisional loss term scales with $r^{2}$. Thus, larger particles will be dominated by the radiative terms and the comparably inefficient collisional loss will result in large particles being warmer than smaller ones.

Instead of assuming steady state conditions to derive the equilibrium temperature, the explicit time dependence of $T_{P}$ can be solved for a given heat capacity of the particles (e.g. Chase et al., 1998 for hematite). We find that the time for a $2 \mathrm{~nm}$ hematite particle to reach equilibrium temperature is less than $0.1 \mathrm{~s}$ for conditions at $87 \mathrm{~km}$.

\subsection{Case 2: dirty ice - Maxwell-Garnett equation for effective dielectric permittivity}

Mesospheric ice particles are believed to not only consist of ice but to include other materials e.g. the meteor smoke particles which were found by Hervig et al. (2012) with a smoke volume 
fraction of up to $3 \%$. The influence of meteor smoke contaminations on the ice particle equilibrium temperature has already been studied by Eidhammer and Havnes (2001), who adapted the refractive index in the infrared regime accordingly. We use the effective medium approximation (Garnett, 1904) for calculating the optical properties of ice mixed with a specific volume fraction $\eta_{1}$ of meteoric smoke. This can be done with the Maxwell-Garnett equation (Bohren and Huffman, 1983; Choy, 1999) under the assumption that all inclusions are spherical. This yields

$\epsilon_{e f f}=\epsilon_{0}+\frac{3 \eta_{1} \gamma_{1}}{1-\eta_{1} \gamma_{1}} \epsilon_{0}$

where

$\gamma_{1}=\frac{\epsilon_{1}-\epsilon_{0}}{\epsilon_{1}+2 \epsilon_{0}}$

where $\epsilon_{0}$ is the dielectric permittivity of the material which is in the inclusion and $\epsilon_{1}$ is the dielectric permittivity of the surrounding material. The effective or average permittivity can now be used to describe the optical properties of dirty ice by converting $\epsilon_{\text {eff }}$ into the refractive index and inserting the effective index into the calculation of the absorption efficiency. The subsequent equilibrium particle temperatures for ice-smoke mixtures are calculated as described in Section 2.1.

\section{Heterogeneous nucleation rate}

The temperature of a condensation nucleus critically influences the nucleation rate, which describes the number density of germs generated per time. We therefore next derive an expression for a MSP temperature dependent nucleation rate.

\subsection{Water vapor fluxes}

The flux of water vapor molecules to a surface can be expressed as Pruppacher and Klett (1997, p. 163)

$w^{\downarrow}=p_{\mathrm{H}_{2} \mathrm{O}} /\left(2 \pi m_{w} k_{b} T_{A}\right)^{1 / 2}$

where $p_{\mathrm{H}_{2} \mathrm{O}}$ is the water vapor partial pressure, $m_{w}$ the mass of one water molecule and $T_{A}$ is the surrounding gas and the vapor temperature. These impinging water molecules will stick with a probability of $\alpha_{d}$, the so-called mass deposition coefficient, to the surface. For ice surfaces at mesospheric temperatures, which we consider in the following, $\alpha_{d}$ is assumed to be 1 (Brown et al., 1996). The flux of molecules leaving the ice phase cannot be computed a priori, so we follow the usual assumption that the detachment of water molecules depends on the properties of the ice phase alone. Under equilibrium conditions, when the water vapor pressure is equal to the saturation vapor pressure over ice $p_{\text {sat }}$, the two fluxes must be equal. This yields (Pruppacher and Klett, 1997, p. 165)

$w^{\uparrow}=p_{\text {sat }}\left(T_{P}\right) /\left(2 \pi m_{w} k_{b} T_{P}\right)^{1 / 2}$

where $T_{P}$ is the temperature of the ice phase. Motivated by the calculations presented in Section 2 we do not follow the usual assumption that $T_{P}=T_{A}$. Instead, we clearly distinguish all terms in the deduction of the nucleation rate which are given by the particle temperature from those influenced by the temperature of the surrounding atmosphere.

\subsection{Critical radius and nucleation barrier}

It is well known that the curvature of an ice particle affects the saturation vapor pressure above its surface (Kelvin effect). For small particles the saturation vapor pressure is increased as compared to a flat surface, i.e., $p_{\text {sat }}(T, r)=p_{\text {sat }}(T) \exp \left(2 m_{w} \sigma / k_{b} T \rho_{\text {ice }} r\right)$ with surface tension $\sigma$, ice density $\rho_{\text {ice }}$ and radius $r$ of a spherical ice particle. The outflux given by Eq. (12) thus becomes radius dependent. There exists a critical radius $r_{\text {crit }}$ where both fluxes are equal

$w^{\uparrow}\left(r_{\text {crit }}\right)=w^{\downarrow}$

$r_{\text {crit }}=\frac{2 m_{w} \sigma}{k_{b} T_{P} \rho_{\text {ice }} \ln S_{z}}$

where $S_{z}=p_{\mathrm{H}_{2} \mathrm{O}} / p_{\text {sat }}\left(T_{P}\right)\left(\sqrt{T_{P} / T_{A}}\right)$. For radii smaller than $r_{\text {crit }}$, the outflux is larger than the influx leading to an evaporation of the ice germ. However, if the ice germ overcomes the critical radius, the ice particle will continue to grow since $w^{\downarrow}>w^{\uparrow}\left(r>r_{\text {crit }}\right)$. The energy barrier separating those two regimes is given by (see Eq. (A.7) in the appendix)

$\Delta G_{\text {crit }}=\frac{4}{3} \pi \sigma r_{\text {crit }}^{2}=\frac{16 \pi \sigma^{3} m_{w}^{2}}{3\left(k_{b} T_{P} \rho_{\text {ice }} \ln S_{z}\right)^{2}}$.

Note that the critical radius is shifted to larger radii if the particle is warmer than the surrounding atmosphere. This modification of $r_{\text {crit }}$ is already implicitly found in the work of Pound et al. (1954) and has also been deduced by Lazzati (2008), who studied nucleation under non-local thermodynamic equilibrium conditions.

\subsection{Nucleation rate}

Nucleation occurs when an ice cluster exceeds its critical radius and starts growing in a supersaturated environment. On a molecular level, this will be the case when a cluster of critical size $r_{\text {crit }}$ is joined by an additional water molecule. Two joining mechanisms are possible: the first mechanism is the direct deposition of water molecules from the gas phase. If the critical cluster forms on a substrate such as MSP, water molecules adsorbed onto the substrated can join the cluster by surface diffusion, which is the second mechanism. Following Keesee (1989), we consider surface diffusion as the dominant process. The adsorbed water molecules are heated due to the warmer substrate and we assume that they reach the particle temperature within a few diffusion steps.

The nucleation rate per unit surface area can be expressed as the number density of clusters of critical size $c_{n_{\text {crit }}}$ times the rate $\mu$ an adsorbed molecule joins the cluster.

The number density of clusters of critical size as given in Eq. (A.6) holds for homogeneous nucleation, where a complete sphere is formed. For heterogeneous nucleation, only an ice cap instead of the complete sphere needs to be formed on the substrate, which is in our study the meteor smoke particle. The volume and surface of the ice cap, which determines the required energy for the formation of the ice cap, depends on the contact angle $\theta$ and also on the radius ratio $x=r_{N} / r_{\text {crit }}$ with the nucleus radius $r_{N}$. The Gibbs free energy for the formation of an ice cap is therefore reduced by a geometrical factor $f$ (Fletcher, 1958, 1959):

$$
\begin{aligned}
2 f(m, x)= & +\left(\frac{1-m x}{g}\right)^{3}+x^{3}\left\{2-3\left(\frac{x-m}{g}\right)+\left(\frac{x-m}{g}\right)^{3}\right\} \\
& +3 m x^{2}\left\{\frac{x-m}{g}-1\right\}
\end{aligned}
$$

where $g=\sqrt{1+x^{2}-2 m x}$ and $m=\cos \theta$. The number density of critical cluster is then given by Eq. (A.6) with the modified critical Gibbs free energy

$c_{n_{\text {crit }}}=c_{1} \exp \left(-\frac{f \Delta G_{\text {crit }}}{k_{b} T_{P}}\right)$

where $c_{1}$ is the number density of adsorbed monomers.

The joining frequency per molecule is given by $\nu \exp \left(-\Delta G_{\mathrm{sd}} /\left(k_{b} T_{P}\right)\right)$ with the typical vibration frequency of an adsorbed molecule $\nu$ and the surface diffusion activation energy 
$\Delta G_{\mathrm{sd}}$. All monomers in the position to join the cluster are assumed to be located in an annulus of area $2 \pi r_{\text {crit }} \bar{\delta} \sin \theta$ around the cluster with the mean diffusion length $\bar{\delta}$. Hence, the joining rate $\mu$ can be expressed as

$\mu=c_{1} 2 \pi r_{\text {crit }} \bar{\delta} \sin \theta \cdot \nu \exp \left(-\frac{\Delta G_{\mathrm{sd}}}{k_{b} T_{P}}\right)$.

This leads to a nucleation rate $J^{\prime}=Z \mu c_{n_{\text {crit }}}$ (Sigsbee, 1969, Eq. 69) per unit surface area of

$J^{\prime}=2 \pi r_{\text {crit }} \bar{\delta} \sin \theta \nu c_{1}^{2} Z \exp \left(\frac{-f \Delta G_{\text {crit }}-\Delta G_{\text {sd }}}{k_{b} T_{P}}\right)$

where the Zeldovich factor for heterogeneous nucleation is defined as $Z=\left(f \Delta G_{\text {crit }} /\left(3 n_{\text {crit }}^{2} \pi k_{b} T_{P}\right)\right)^{1 / 2}$ and the number of molecules in an ice cap of critical size $n_{\text {crit }}=4 \pi r_{\text {crit }}^{3} \rho_{\text {ice }} f /\left(3 m_{w}\right)$ (Sigsbee, 1969, Eqs. 35 and 72). The Zeldovich factor takes deviations of the cluster size distribution from its equilibrium distribution into account.

The surface concentration of monomers $c_{1}$ is estimated from the desorption flux $w^{\uparrow}=c_{1} \nu \exp \left(-\Delta G_{\mathrm{des}} /\left(k_{b} T_{P}\right)\right)$ (Pruppacher and Klett, 1997, p. 299) with the energy of desorption $\Delta G_{\text {des }}$. This desorption flux needs to be balanced by the influx given in Eq. (11), leading to

$c_{1}=\frac{p_{\mathrm{H}_{2} \mathrm{O}}}{\nu\left(2 \pi m_{w} k_{b} T_{A}\right)^{1 / 2}} \exp \left(\frac{\Delta G_{\mathrm{des}}}{k_{b} T_{P}}\right)$.

Accordingly, the nucleation rate per particle $J / N_{N}=4 \pi r_{N}^{2} J^{\prime}$ becomes

$J / N_{N}=\frac{4 \pi r_{N}^{2} Z \bar{\delta} p_{\mathrm{H}_{2} \mathrm{O}}^{2} r_{\text {crit }} \sin \theta}{\nu m_{w} k_{b} T_{A}} \exp \left(\frac{2 \Delta G_{\text {des }}-\Delta G_{\text {sd }}-f \Delta G_{\text {crit }}}{k_{b} T_{P}}\right)$.

This nucleation rate with the two different temperature $T_{A}$ and $T_{P}$ accords with those deduced for molecular beam experiments, where the gas emanates from a source with higher temperature than the substrate (e.g., Pound et al., 1954).

\section{Results: equilibrium temperatures of MSP and dirty ice particles and corresponding nucleation rates}

\subsection{Model comparison}

To check our particle temperature model, we initially compare our results to calculations of Espy and Jutt (2002) (EJ hereafter) for ice particles with three different radii using the MAC-SINE (Middle Atmosphere Co-operation-Summer in Northern Europe) atmosphere (see Fig. 2 in EJ and explanation therein) as a typical polar summer atmosphere. This MAC-SINE background atmosphere is the same as the one used by EJ. However, in comparison to their model, we have made a couple of simplifications. EJ performed complete radiative transfer calculations to determine the radiance at the particle altitude. We simplified this step by assuming black body radiation. We also assume in contrast to EJ that all winds and particle fall velocities are negligible compared to the thermal velocity which simplifies the equation in the collision term. All parameters used for the recalculation are shown in comparison to EJ in Table 1. The left panel in Fig. 1 shows the resulting temperature profiles of this calculation in comparison with the results of EJ. The temperature difference increases for all particle sizes with increasing altitude, which is the result of less efficient cooling due to the decreasing density. This increase of temperature difference also depends on the size of the particles. All radiation terms scale with $r^{3}$ whereas the collision term scales with $r^{2}$ only. This means that the source terms become more effective with increasing $r$.

The temperature values calculated are always smaller in comparison to EJs results. The difference increases with increasing radius and altitude. This fact becomes much more visible in the right panel of Fig. 1 where the differences between the model results are plotted. Overall, the differences are small, i.e. below $3 \%$ thus justifying the simplifications made in our approach.

\subsection{Equilibrium temperature of meteor smoke and dirty ice particles}

Since meteor smoke particles are assumed to be one of the major nucleation germs for mesospheric ice particles we attempt

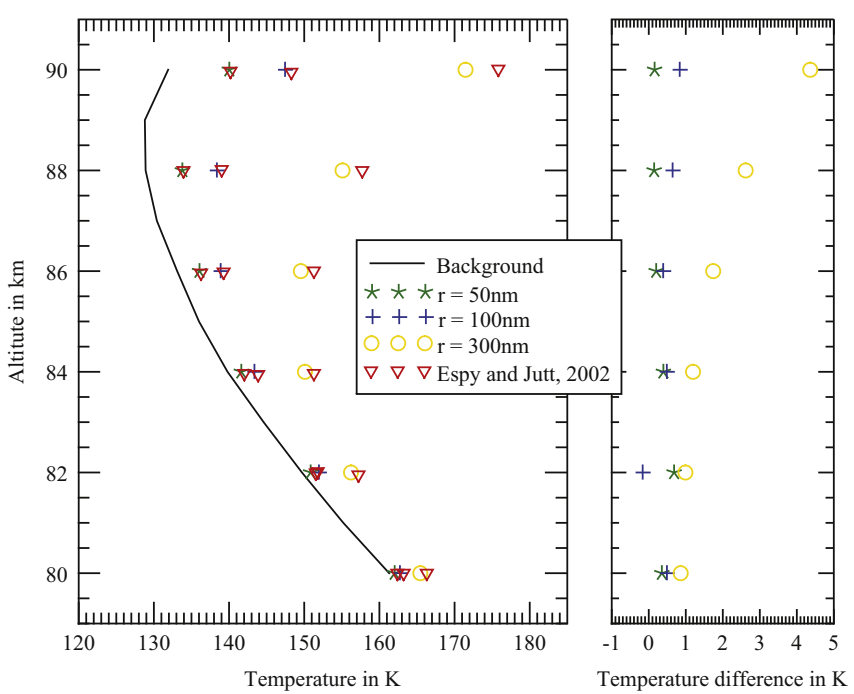

Fig. 1. Left panel: equilibrium temperature profiles for three different ice particle radii $(50,100$ and $300 \mathrm{~nm})$. The black curve shows the MAC-SINE background temperature, the green, blue and yellow symbols are the equilibrium temperatures for ice particles with a 50, 100 and $300 \mathrm{~nm}$ radius, respectively. The red triangles display the temperature values of Espy and Jutt (2002) for the same radii. Right panel: temperature differences between Espy and Jutt (2002) for ice and our calculations for each particle radius as a function of altitude. The green asterisks indicate the discrepancies for $50 \mathrm{~nm}$ radius, the blue crosses for $100 \mathrm{~nm}$ radius and the yellow circles for $300 \mathrm{~nm}$ radius. (For interpretation of the references to color in this figure caption, the reader is referred to the web version of this article.)

Table 1

Comparison of model parameters.

\begin{tabular}{|c|c|c|}
\hline Parameter & Espy and Jutt (2002) & Model \\
\hline Atmospheric profiles & Lübken and et al. (1990) & Lübken and et al. (1990) \\
\hline Spectra & MODTRAN & Blackbody \\
\hline Absorption efficiency $Q_{a b s}$ & van de Hulst (1981) & Bohren and Huffman (1983) \\
\hline Ice refractive index & See Espy and Jutt (2002) subsection model implementation & Warren and Brandt (2008) \\
\hline Wavelength range & $200 \mathrm{~nm}-333 \mu \mathrm{m}$ & $44 \mathrm{~nm}-1 \mathrm{~m}$ \\
\hline therm. accommodation coeff. $\alpha$ & 0.5 & 0.5 \\
\hline Particle radii $(\mathrm{nm})$ & $50,100,300$ & $50,100,300$ \\
\hline Albedo $A$ & 0.30 & 0.30 \\
\hline Wind, sedimentation velocity & $s \neq 0$ & $s=0$ \\
\hline
\end{tabular}


Table 2

Refractive indices of meteor dust.

\begin{tabular}{lll}
\hline Material & Wavelength (m) & Reference \\
\hline Olivine $\left(\mathrm{Mg}_{1.9} \mathrm{Fe}_{0.1} \mathrm{SiO}_{4}\right)$ & $2 \times 10^{-7}-8.2 \times 10^{-4}$ & $\begin{array}{l}\text { Fabian et al. (2001), } \\
\text { Zeidler et al. (2011) }\end{array}$ \\
$\begin{array}{l}\text { Hematite }\left(\mathrm{Fe}_{2} \mathrm{O}_{3}\right) \\
\text { Magnesium-iron-silicates } \\
\left(\mathrm{Mg}_{X} \mathrm{Fe}_{1-X} \mathrm{SiO}_{3}\right)\end{array}$ & $1 \times 10^{-7}-1 \times 10^{-3}$ & $\begin{array}{l}\text { AlU Jena (2012) } \\
\text { Jaeger et al. (1994) }\end{array}$ \\
$\begin{array}{c}\text { Magnesiowüstite } \\
\left(\mathrm{Mg}_{X} \mathrm{Fe}_{1-X} \mathrm{O}\right)\end{array}$ & $2 \times 10^{-7}-5 \times 10^{-4}-5 \times 10^{-4}$ & $\begin{array}{l}\text { Dorschner et al. (1995) } \\
\text { Henning et al. (1995) }\end{array}$ \\
\hline
\end{tabular}

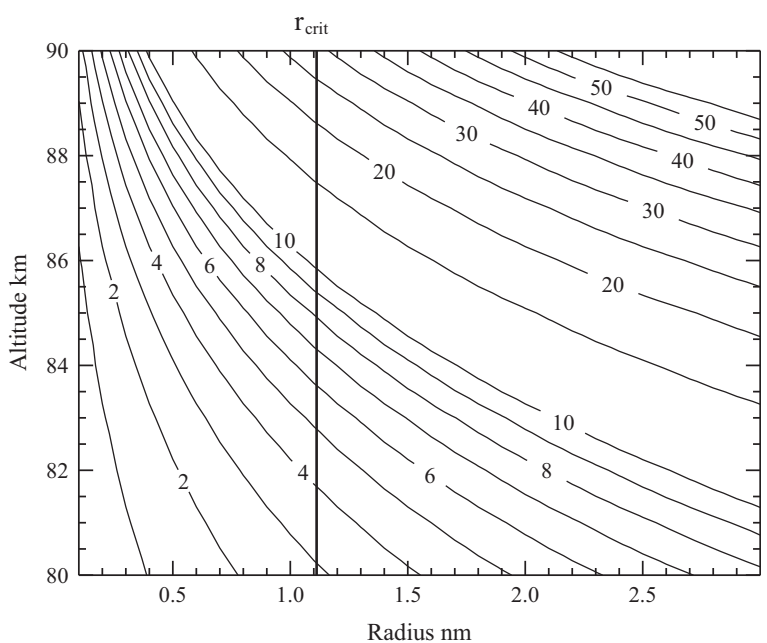

Fig. 2. Temperature differences in $\mathrm{K}$ between the background and the magnesiowüstite particle equilibrium temperature as a function of particle radius and altitude. The dashed line indicates the critical radius for heterogeneous nucleation for typical summer polar mesospheric conditions.

to quantify the nucleation conditions for these particles in the mesosphere. Therefore we used the model described in Section 2 and applied refractive indices of several materials assuming that the optical properties are not altered due to the condensation of meteor dust to meteor smoke. Table 2 shows the used materials, the wavelength range of the refractive index data and the reference where the data was taken from. These dust materials have relatively high values for the imaginary part of the refraction index which describes the ability of the material to absorb light at a specific wavelength. Hence we expect much higher equilibrium temperatures.

Mesospheric ice particles are known to exist in the summer high latitude mesopause region between roughly 80 and $90 \mathrm{~km}$. Typical critical radii in this regime of atmosphere are in the range of about $1 \mathrm{~nm}$ (Rapp and Thomas, 2006). Hence we calculate the equilibrium temperature for MSP in an altitude range of 80-90 km and a radius range of $0.1-3 \mathrm{~nm}$. Fig. 2 shows the model results for a magnesiowüstite $\left(\mathrm{Mg}_{0.1} \mathrm{Fe}_{0.9} \mathrm{O}\right)$ particle. Plotted are the temperature differences between the particle equilibrium temperature and the MAC-SINE background temperature as a function of particle radius and altitude. Since the temperature differences are positive the magnesiowüstite particles are warmer than the background temperature. This effect increases with increasing particle radius as a result of more effective radiative heating compared to the loss by collisions. The temperature difference also increases with increasing altitude due to the decreasing air density and the corresponding cooling by collisions with air molecules. Even at small particle radii this leads to relatively large temperature differences of several Kelvin between the particle and the surrounding atmosphere.

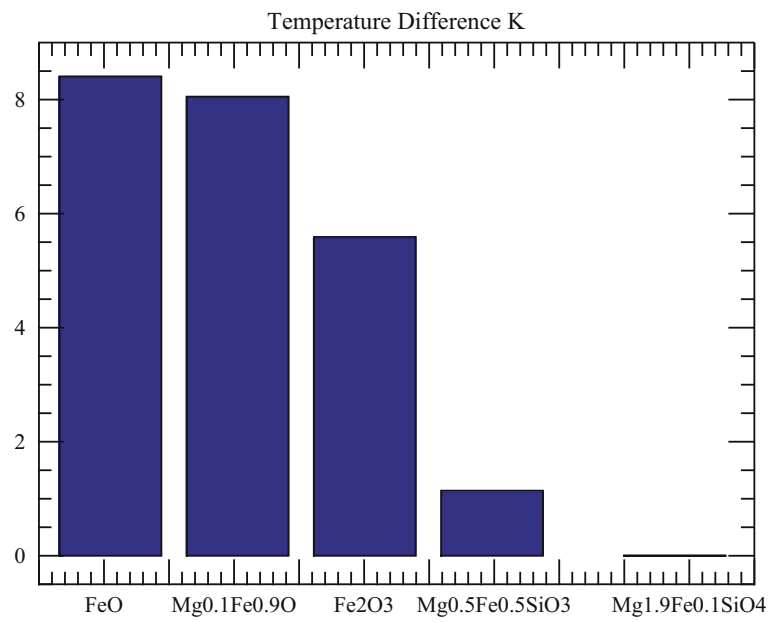

Fig. 3. Absolute temperature difference between the surrounding atmosphere and a MSP with radius $r_{\text {crit }}$ at $85 \mathrm{~km}$ consisting of iron oxide (FeO), magnesiowüstite $\left(\mathrm{Mg}_{0.1} \mathrm{Fe}_{0.9} \mathrm{O}\right)$, hematite $\left(\mathrm{Fe}_{2} \mathrm{O}_{3}\right)$, magnesium-iron-silicate $\left(\mathrm{Mg}_{0.5} \mathrm{Fe}_{0.5} \mathrm{SiO}_{3}\right)$ and olivine $\left(\mathrm{Mg}_{1.9} \mathrm{Fe}_{0.1} \mathrm{SiO}_{4}\right)$.

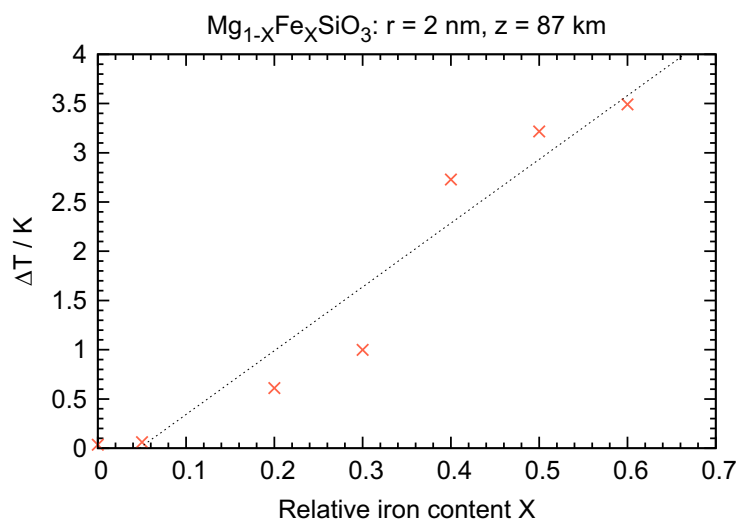

Fig. 4. Temperature difference between background atmosphere and magnesium iron silicate particles with varying iron content $X$. The particle radius is $2 \mathrm{~nm}$ and the temperature of the background atmosphere is $T_{P}=130.4 \mathrm{~K}$.

Fig. 3 shows the temperature difference between MSP of different materials and the background for a particle radius of $1.1 \mathrm{~nm}$, a typical critical radius for the summer mesopause region. The largest temperature difference is found for a meteor smoke material of iron oxide. This is also the material with the highest iron content. Apparently there is a strong dependence on iron content. This becomes much clearer in Fig. 4, which shows the equilibrium temperature of a $2 \mathrm{~nm}$ particle at $87 \mathrm{~km}$ consisting of magnesium, iron and silicate. To investigate the impact of different relative iron contents we used several magnesium-iron-silicates with different relative iron content $X$ and analyzed on the equilibrium temperature change. We used optical data sets of $\mathrm{Mg}_{1-X} \mathrm{Fe}_{X} \mathrm{SiO}_{3}$ from Jaeger et al. (1994) and Dorschner et al. (1995). We find a clear positive correlation of the relative iron content $X$ and the particle temperature $T_{P}$. Since nucleation is highly temperature dependent we suggest that this should have an impact on the possible materials for nuclei of mesospheric ice.

As stated above mesospheric ice particles are assumed to be formed on meteor smoke. Recent observations indicate that these ice particles are not made of pure ice but are "dirty" in the sense that they include MSP (Hervig et al., 2012). It is therefore important to know what optical properties this mixed medium has and how this influences the temperature of those dirty ice particles. We applied the Maxwell-Garnett theory described in Section 2.2 to obtain an effective refractive index for the mixed 
media. With this effective refraction index we derived the equilibrium temperature as described in Section 2. We chose $0.01 \%, 0.3 \%$ and $3 \%$ volume fraction of meteor smoke in the ice particles which is the minimum, mean and maximum value from the analysis of Hervig et al. (2012). The model results show that with increasing volume fraction of meteoric smoke in the dirty ice particles the temperature difference between those particles and pure ice particles increases as shown in Fig. 5. There is no linear relationship between the change in temperature difference and the change in meteoric smoke volume fraction in the ice. The relative change of the temperature difference increases with increasing volume fraction. Looking at the mean value of the volume fraction, i.e. $0.3 \%$, it turns out that there is a significant difference between pure and dirty ice equilibrium temperature (Fig. 5, middle panel) at radii bigger than $50 \mathrm{~nm}$ and altitudes higher than $82 \mathrm{~km}$. Nevertheless the model calculations also show that dirty ice particles which are

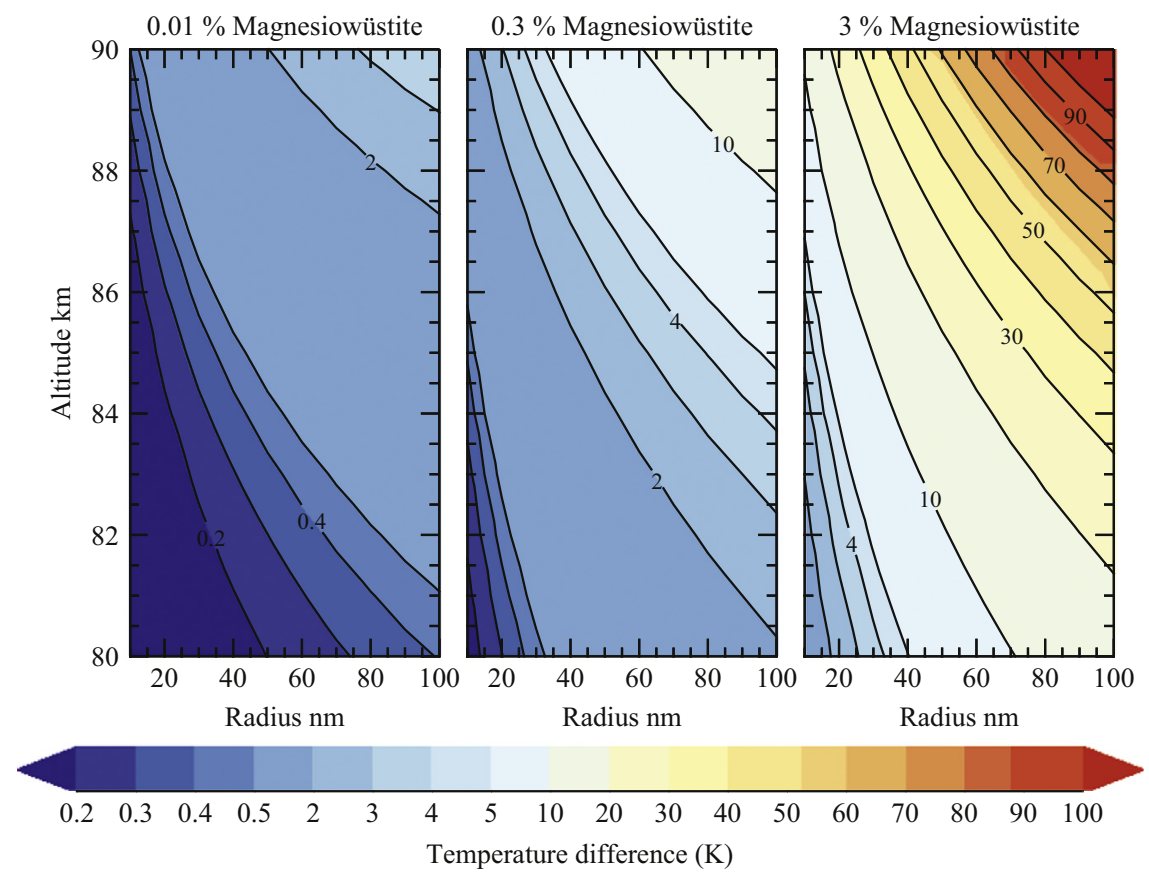

Fig. 5. Temperature difference between dirty and pure ice particles in Kelvin as a function of particle size and altitude. The three panels show dirty ice with a $0.01 \%$ (left), $0.3 \%$ (middle) and 3\% (right) volume fraction of $\mathrm{Mg}_{0.1} \mathrm{Fe}_{0.9} \mathrm{O}$.
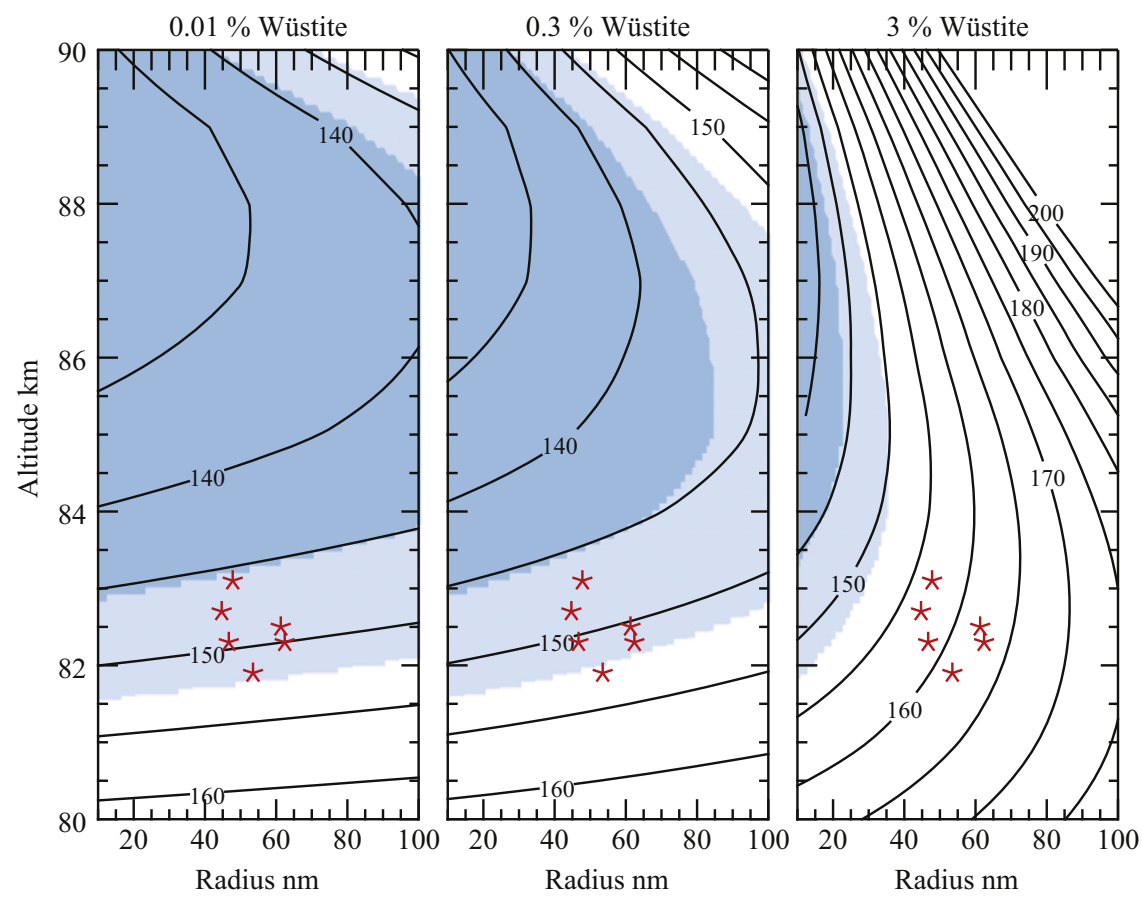

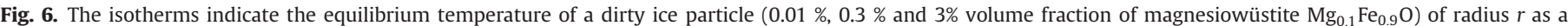

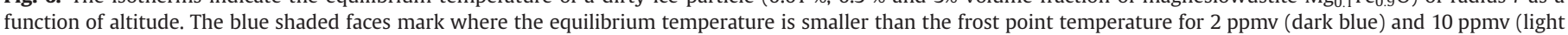

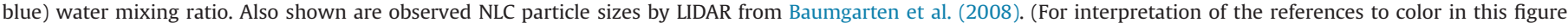
caption, the reader is referred to the web version of this article.) 
contaminated by high iron content material are likely to exist in a wide range of altitude and size (Fig. 6 middle panel) for typical mesosphere water mixing ratios. This mainly concerns the forming region of mesospheric ice particle which is between 90 and $85 \mathrm{~km}$ depending on the mesopause altitude (Rapp and Lübken, 2004). Also indicated in Fig. 6 are altitudes and radii of NLC particles measured by LIDAR (Baumgarten et al., 2008). We note that in a statistical sense these particles were mostly located at the boundary of the existence regime of dirty ice for 10 ppmv water mixing ratio.

\subsection{Heterogeneous nucleation rate}

For the interpretation of the temperature differences we next calculate nucleation rates for different surface temperatures of the nuclei at polar summer mesospheric conditions. Following Rapp and Thomas (2006) we assume $T_{A}=130 \mathrm{~K}$, $\sigma=\left(141.0-0.15 \cdot\left(T_{P}[\mathrm{~K}]\right)\right) \times 10^{-3} \mathrm{~J} / \mathrm{m}^{2}$, the atmospheric pressure is $p=0.3 \mathrm{~Pa}$, the bulk density of ice $\varrho$ is $930 \mathrm{~kg} / \mathrm{m}^{3}$, the water vapor mixing ratio $W$ is 2 ppmv. The parametrization of the saturation vapor pressure is taken from Murphy and Koop (2005). For $m=\cos \theta$ we chose $0.95, \bar{\delta}=0.1 \mathrm{~nm}, \nu_{S}=10^{13} \mathrm{~s}^{-1}$. The diffusion free energy $\Delta G_{\mathrm{sd}}$ is $0.1 \cdot \Delta G_{\mathrm{des}}$ and we use the values originally introduced by Seki and Hasegawa (1983) $\left(\Delta G_{\mathrm{des}}=2.9 \times 10^{-20} \mathrm{~J}\right.$ and $\left.\Delta G_{\text {sd }}=2.9 \times 10^{-21} \mathrm{~J}\right)$ which are estimated from the wetting heat of $\mathrm{H}_{2} \mathrm{O}$ to $\alpha-\mathrm{SiO}_{3}$. Fig. 7 shows the nucleation rates per nucleus $J / N_{N}$ for different surface temperatures $T_{P}$ in the lower panel. The upper panel shows the nucleation rate ratios between $J\left(T_{P}\right)$ and $J\left(T_{A}\right)$. As expected the rates become smaller if the surface temperature increases due to the higher desorption flux. This means that more molecules will leave the germ and the net flux onto the nucleus will decrease. This effect has a large impact notably at small radii. A temperature difference of $3 \mathrm{~K}$ for particle with radius of $3 \mathrm{~nm}$ causes a decrease of the nucleation rate by a factor of $10^{5}$. This dramatic drop of the nucleation rate implies that meteor smoke particles consisting of material with high equilibrium temperatures become ineffective nuclei for mesospheric ice particles.
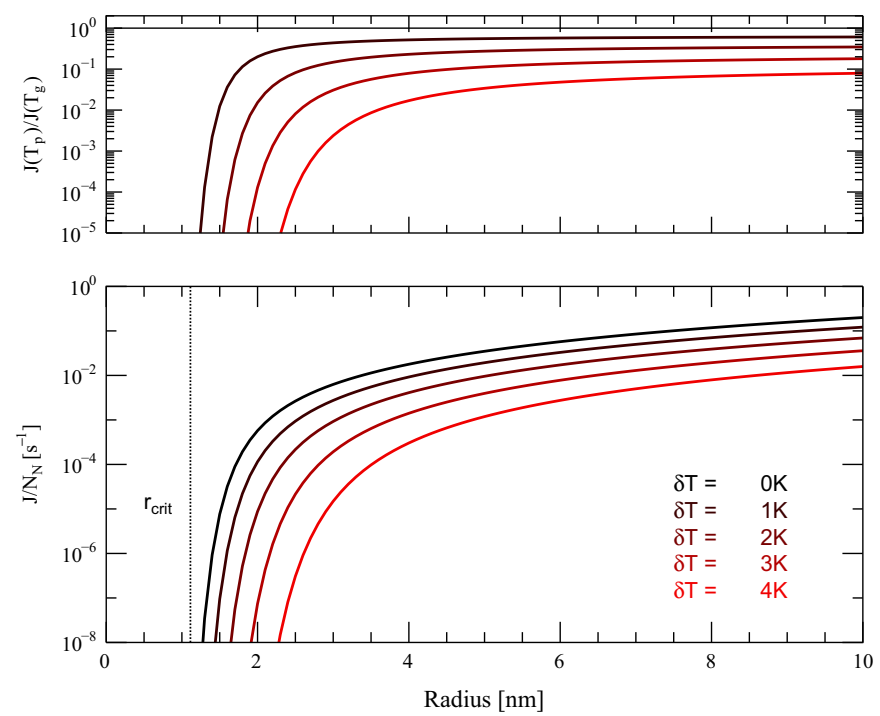

Fig. 7. Lower panel: heterogeneous nucleation rate per nucleus $J\left(T_{P}\right) / N_{N}$ as a function of radius and for different temperature differences $(0,1,2,3$ and $4 \mathrm{~K})$ between background atmosphere and particle $\left(T_{P}-T_{A}\right)$. The dotted line marks the critical radius $r_{\text {crit }}$ for the given atmospheric conditions (see text for details). Upper panel: ratio between the nucleation rates including temperature difference and the nucleation rate without temperature difference.

\section{Effect on NLC evolution}

Finally, we use a one-dimensional version of CARMA, the Community Aerosol and Radiation Model for Atmospheres, to demonstrate the impact of an increased MSP temperature on the evolution of NLC. CARMA is a microphysical model which has been used to study a wide range of aerosols and clouds in the Earth's atmosphere as well as on other planets. The original one-dimensional model was developed by Turco et al. (1979) and Toon et al. (1979) for modeling polar stratospheric clouds. It was extended to three dimensions (Toon et al., 1988) and adopted to mesospheric clouds by Turco et al. (1982) and Jensen and Thomas (1989).

Our setup is identical to the one used by Rapp and Thomas (2006), except for the implementation of the new nucleation rate given in Eq. (21) and the correction of a sign error in the parameterization of the surface tension. We assume a temperature difference between MSP and ambient atmosphere which varies with altitude but does not depend on the radius of the MSP. The altitude profile is calculated for a $2.5 \mathrm{~nm}$ magnesium-iron-silicate $\left(\mathrm{Mg}_{0.5} \mathrm{Fe}_{0.5} \mathrm{SiO}_{3}\right)$ particle and scaled in a way, so that the temperature difference $\Delta T$ at $87 \mathrm{~km}$ is $1 \mathrm{~K}, 3 \mathrm{~K}, 5 \mathrm{~K}$ and $7 \mathrm{~K}$. Fig. 8 shows the obtained ice particle number densities for the different $\Delta T$ and also the reference case of $\Delta T=0 \mathrm{~K}$. In Fig. 9 we show the corresponding effective radii of the obtained ice particles for the reference case and for $\Delta T=7 \mathrm{~K}$.

The impact of MSP being warmer than the background atmosphere has a striking effect on the ice particle number densities. While in the reference case densities of more than $100 \mathrm{~cm}^{-3}$ develop, a temperature increase of $5 \mathrm{~K}$ reduces the maximum ice particle density by a factor of 100 and at $\Delta T=7 \mathrm{~K}$ even less than 0.1 particles per $\mathrm{cm}^{3}$ occur. There are basically three factors contributing to the reduced ice particle number densities. First of all, the characteristic time of nucleation is reduced by several orders of magnitude (compare to upper panel of Fig. 7) such that less particles are formed per time. Secondly, for warmer smoke particles the saturation vapor pressure increases, so that the vertical extent of the supersaturated region, the region where newly formed ice particles are able to persist, is diminished. Finally, the minimum size of MSP acting efficiently as ice nuclei is shifted to larger radii for warmer MSP. In the reference scenario the large number of ice germs formed in the first few time steps compete for the available water vapor, which leads to a rapid decrease of the supersaturation and limits further ice particle growth. If less ice germs are formed due to warmer MSP, they are not able to effectively deplete the available water vapor. Consequently, the ice particles grow rapidly to sizes much larger than in the reference case, as shown in Fig. 9. Note that the absolute number of ice particles is expected to decrease even further when a MSP profile for mesospheric summer conditions with reduced MSP densities (Megner et al., 2008; Bardeen et al., 2008) is used.

Assuming a constant $\Delta T$ for MSP of all radii definitely contradicts the results discussed in Fig. 2, but we note that there is a justification for this first and simplified implementation: the nucleation rate per particle has a steep increase for radii larger than $r_{\text {crit }}$, whereas the MSP distribution falls off exponentially. Thus the nucleation rate will peak at a certain radius, where $J=J / N_{\text {Smoke }} \cdot N_{\text {Smoke }}$ has a maximum. For the conditions chosen in Fig. 7 and the MSP profile implemented in CARMA (see Rapp and Thomas, 2006), the highest nucleation rate occurs at a radius of about $2 \mathrm{~nm}$ with peak width (FWHM) of less than $1 \mathrm{~nm}$. Note that the radius of the maximum nucleation rate is shifted to larger radii for warmer MSP. With these arguments in mind, varying $\Delta T$ can be interpreted as a temperature variation due to changing the iron content of MSP. As shown in Fig. 4, a larger relative iron content leads to warmer MSP and therefore greatly reduced ice particle number densities. These CARMA simulations aimed at demonstrating the principal effect of a reduced nucleation 
a

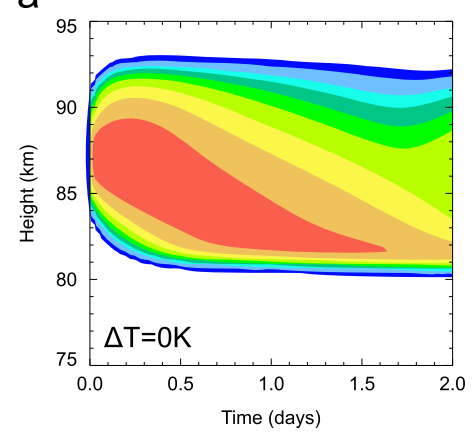

d

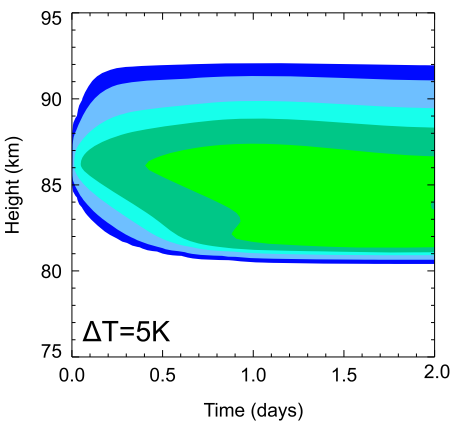

b

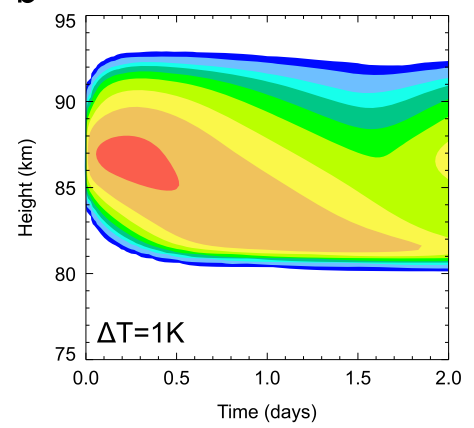

e

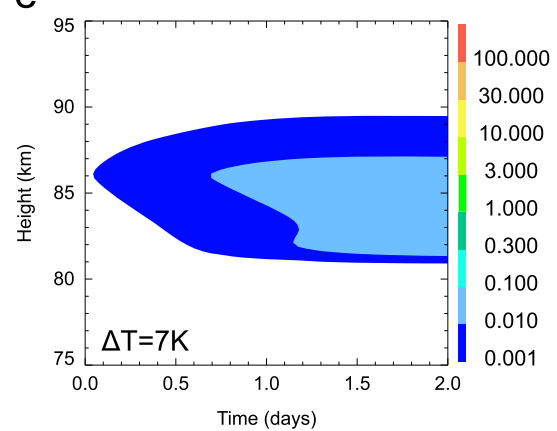

C

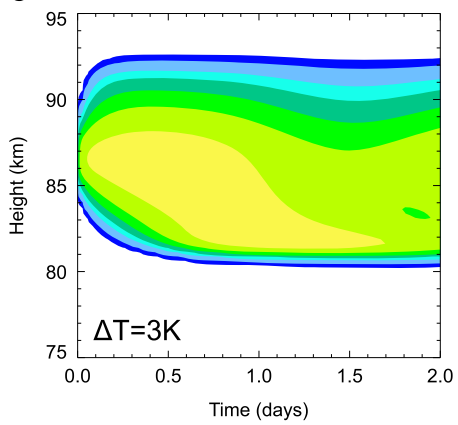

0.000

.000

1.000

0.300

0.100

0.010

0.001

Fig. 8. Ice number densities with varying temperature differences between MSP and the ambient atmosphere. $\Delta T$ refers to the temperature difference at $87 \mathrm{~km}$.

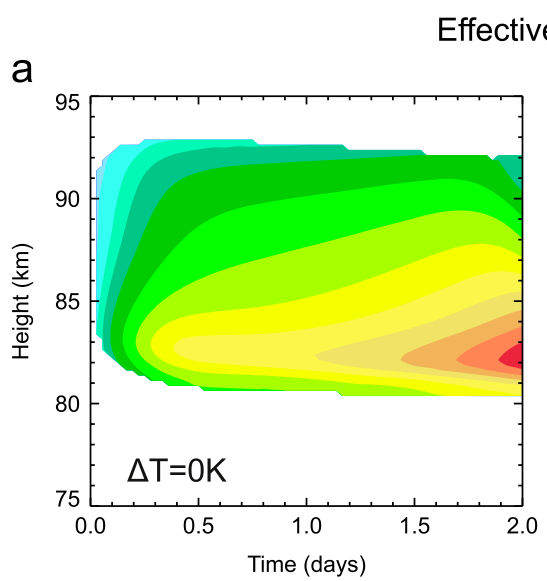

b

Fig. 9. Effective radius of ice particles for the reference case with $\Delta T=0 \mathrm{~K}$ and $\Delta T=7 \mathrm{~K}$.

rate. To exclude additional effects based on varying background conditions, we utilize a steady temperature profile. Of course, this highly differs from mesospheric conditions, where gravity wave induced temperature fluctuations determine the microphysical processes, e.g. the onset of nucleation in the cold phase of waves. We note that these $1 \mathrm{~d}$ simulations also show artificial oscillations of the NLC brightness which are caused by cycles of freeze drying the mesospheric air and subsequent re-moistening by eddy diffusion and advective transport of water vapor (e.g., Sugiyama, 1996). In future, the full iterative scheme from Eq. (9) will be implemented in CARMA and different meteor smoke compositions will be analyzed in their efficiency to act as nucleation germs.

\section{Discussion}

The presented results are based on simple assumptions and most of all are basic relations such as black body radiation. We find that meteor smoke particles are warmer by several Kelvin than the surrounding atmosphere, depending on their composition, size and altitude. This increased temperature of MSP reduces the nucleation rates by several orders of magnitude. The nucleation rate itself is subject to a high degree of uncertainty, as variables such as the surface tension or contact angles are poorly known for mesospheric conditions. Additionally it is unclear, whether all bulk material properties can be applied to a system consisting of only a few molecules. However, until experimental results for mesospheric nucleation rates are available, the presented rates are the best estimates based on the current classical nucleation theory for mesospheric conditions (e.g., Keesee, 1989). It is important to note that, depending on the background conditions, a MSP temperature increase of a few Kelvin might not be so critical, as gravity wave can induce temperature variations in the range of $10 \mathrm{~K}$ (e.g., Rapp, 2002) which might compensate this effect. For conditions close to the edge of nucleation with only low supersaturation, we expect the temperature increase of MSP to have a much greater impact 
than under extreme conditions such as those measured for example at Spitsbergen (Lübken et al., 2009).

For mixed materials, i.e. dirty ice we showed that these particles are likely able to exist in the summer mesopause region. But nevertheless, despite the fact that the dirty ice particle equilibrium temperature is below the frost point temperature for wide ranges of altitude and radius, the nucleation rate calculations for a water mixing ratio of 2 ppmv showed that the nucleation on the iron rich MSP is very inefficient. There have to be further investigations on the forming and especially growing of mesospheric ice with respect to temperature differences between the atmosphere and the nuclei. Lazzati (2008) pointed out that at nonlocal thermodynamic equilibrium the condition $S=1$ does not mark the threshold of nucleation.

We note that our results are in apparent contrast to the results of Petelina and Zasetsky (2009) who derived ice particle temperatures from Atmospheric Chemistry Experiment (ACE) satellite measurements and found the ice particles to be colder than the ambient atmosphere. However, Hervig and Gordley (2010) state that these ambient air temperatures from ACE may possibly be influenced by warm patches of air along the line of sight which might result in a warm bias compared to the localized ice particle temperature measurements. In any case, if those satellite measurements were indeed correct, our results would provide strong support to the conclusion that the observed ice particles do not contain meteor smoke of the considered compositions.

\section{Conclusions}

We calculated equilibrium temperatures for mesospheric ice and meteor smoke particles and investigated its impact on the nucleation of mesospheric ice particles. Therefore we introduced a nuclei temperature dependent heterogeneous nucleation rate. The results of the equilibrium temperature calculations show that under the made assumptions for particle composition MSP are warmer than the environmental atmosphere. The temperature difference is mainly driven by the ability of the material to absorb radiation mainly in the visible range. It turns out that particles with a high relative iron content are much better absorbers and therefore are much warmer than particles with less relative iron content. The nucleation rate calculations showed that even small temperature differences of a few Kelvin between particle and atmosphere temperature lead to a rapid decrease of the nucleation rate at small particle radii. In combination with the equilibrium temperature results we suggest that high iron content materials have to be much more ineffective nuclei and therefore must be less important for mesospheric ice nucleation. The materials to which this applies are, e.g., iron oxide, magnesiowüstite with high relative iron content, hematite and silicates with high relative iron content. In the future, we will further investigate whether the here discussed effects may be partly compensated by temperature fluctuating due to gravity waves and how competing nucleation mechanisms like homogeneous nucleation may change the whole picture.

\section{Acknowledgments}

We greatly appreciated the valuable advice on nucleation rates from Bernd Kärcher.

\section{Appendix A. Number density of clusters of critical size}

In the following we deduce the number density of critical clusters for equilibrium conditions. A steady state is reached when the attachment rate to a cluster with $n-1$ molecules is balanced by the detachment rate of a cluster with $n$ molecules

$w^{\downarrow} A_{n-1} c_{n-1}=w^{\uparrow} A_{n} c_{n}$

where $A$ is the surface area of the cluster and $c_{n}$ the number density of clusters with $n$ molecules. Using Eqs. (11) and (12) and neglecting the surface area difference $\left(A_{n-1} / A_{n}=1\right.$ for sufficiently large cluster), $c_{n}$ can be expressed as

$c_{n}=c_{n-1} S_{z} \exp \left(-\frac{2 m_{w} \sigma}{k_{b} T_{P} \rho_{\text {ice }}}\left(\frac{4 \pi}{3 n v}\right)^{1 / 3}\right)$

where $S_{z}=p_{\mathrm{H}_{2} \mathrm{O}} / p_{\text {sat }}\left(T_{P}\right)\left(\sqrt{T_{P} / T_{A}}\right)$ and $v$ is the molecular volume. $c_{n-1}$ can be expressed through $c_{n-2}$, which in turn can be calculated from $c_{n-3}, \ldots$ and $c_{2}$ eventually from the monomer concentration $c_{1}$ :

$$
\begin{aligned}
& c_{n}=c_{1} \prod_{j=2}^{n} S_{z} \exp \left(-\frac{2 m_{w} \sigma}{k_{b} T_{P} \rho_{\text {ice }}}\left(\frac{4 \pi}{3 j v}\right)^{1 / 3}\right) \\
& =c_{1} \exp \left(n \ln S_{z}-\frac{3 m_{w} \sigma}{k_{b} T_{P} \rho_{\text {ice }}}\left(\frac{4 \pi}{3 v}\right)^{1 / 3} n^{2 / 3}\right) .
\end{aligned}
$$

In the second equation the product has been expressed as a sum within the exponential function, which is then transformed into an integral $\sum_{j=2}^{n} \rightarrow \int_{0}^{n} \mathrm{~d} j$. As we are interested in the number density of critical size clusters, which hold a few hundred molecules, the lower boundary can safely be shifted from $j=2$ to $j=0$. The number density is a monotonically decreasing function of $n$ in an undersaturated environment. For supersaturated conditions $c_{n}$ has a local minimum at $n=n_{\text {crit }}$. Evaluating $n_{\text {crit }}$ from $\partial c_{n} / \partial n=0$ yields

$n_{\text {crit }}=\frac{4 \pi}{3 v}\left(\frac{2 m_{w} \sigma}{k_{b} T_{P} \rho_{\text {ice }} \ln S_{z}}\right)^{3}=\frac{4 \pi}{3 v} r_{\text {crit }}^{3}$.

The number density of clusters of critical size will therefore be

$c_{n_{\text {crit }}}=c_{1} \exp \left(-\frac{\Delta G_{\text {crit }}}{k_{b} T_{P}}\right)$

where

$\Delta G_{\text {crit }}=\frac{16 \pi \sigma^{3} m_{w}^{2}}{3\left(k_{b} T_{P} \rho_{\text {ice }} \ln S_{z}\right)^{2}}$

\section{References}

AIU Jena, 2012. Optical Data. 〈http://www.astro.uni-jena.de/Laboratory/OCDB/ index.html $>$.

Bardeen, C.G., Toon, O.B., Jensen, E.J., Marsh, D.R., Harvey, V.L., 2008. Numerical simulations of the three-dimensional distribution of meteoric dust in the mesosphere and upper stratosphere. J. Geophys. Res. 113 (D17), 202, http: //dx.doi.org/10.1029/2007JD009515.

Baumgarten, G., Fiedler, J., Lübken, F.-J., Cossart, G.V., 2008. Particle properties and water content of noctilucent clouds and their interannual variation. J. Geophys. Res. 113 (D6), http://dx.doi.org/10.1029/2007JD008884.

Bohren, C.F., Huffman, D.R., 1983. Absorption and Scattering of Light by Small Particles. John Wiley \& Sons, New York.

Brown, D.E., George, S.M., Huang, C., Wong, E.K.L, Rider, K.B. Smith, R.S., Kay, B.D. 1996. $\mathrm{H}_{2} \mathrm{O}$ condensation coefficient and refractive index for vapor-deposited ice from molecular beam and optical interference measurements. J. Phys. Chem. 100 (12), 4988-4995, http://dx.doi.org/10.1021/jp952547j.

Chase, M.W., 1998. NIST-JANAF Thermochemical Tables, 4th ed. National Institute of Standards and Technology (U.S.); American Chemical Society, Washington, DC; American Institute of Physics for the National Institute of Standards and Technology, Woodbury, NY (revised edition of JANAF Thermochemical Tables, 2nd ed., 1971).

Choy, T., 1999. Effective Medium Theory: Principles and Applications. Clarendon Press, Oxford.

Czechowsky, P., Rüster, R., Schmidt, G., 1979. Variations of mesospheric structures in different seasons. Geophys. Res. Lett. 6 (6), 459.

Dorschner, J., Begemann, B., Henning, T., Jaeger, C., Mutschke, H., 1995. Steps toward interstellar silicate mineralogy. II. Study of $\mathrm{Mg}$-Fe-silicate glasses of variable composition. Astron. Astrophys. Suppl. 300, 503. 
Ecklund, W.L., Balsley, B.B., 1981. Long-term observations of the arctic mesosphere with the MST radar at poker flat, Alaska. J. Geophys. Res. 86 (A9), 7775-7780.

Eidhammer, T., Havnes, O., 2001. Size dependence of the mesospheric dust temperature and its influence on the noctilucent clouds and polar mesosphere summer echo phenomena. J. Geophys. Res. 106 (A11), 24831-24841.

Espy, P., Jutt, H., 2002. Equilibrium temperature of water-ice aerosols in the highlatitude summer mesosphere. J. Atmos. Sol.-Terr. Phys. 64 (17), 1823-1832.

Fabian, D., Henning, T., Jäger, C., Mutschke, H., Dorschner, J., Wehrhan, O., 2001. Steps toward interstellar silicate mineralogy. Astron. Astrophys. 378 (1), 228-238.

Fiocco, G., Grams, G., Visconti, G., 1975. Equilibrium temperatures of small particles in the Earth's upper atmosphere (50-110 km). J. Atmos. Terr. Phys. 37 (10) 1327-1337.

Fletcher, N.H., 1958. Size effect in heterogeneous nucleation. J. Chem. Phys. 29 (3), $572-576$.

Fletcher, N.H., 1959. On ice-crystal production by aerosol particles. J. Meteorol. 16 (2), 173-180.

Garnett, J.C.M., 1904. Colours in metal glasses and in metallic films. Philos. Trans. R. Soc. A: Math. Phys. Eng. Sci. 203 (359-371), 385-420, http://dx.doi.org/10.1098/ rsta.1904.0024.

Gombosi, T.I., 1994. Gaskinetic Theory. Cambridge University Press, Cambridge.

Gumbel, J., 2003. Influences of ice particles on the ion chemistry of the polar summer mesosphere. J. Geophys. Res. 108 (D8), http://dx.doi.org/10.1029/ 2002JD002413.

Henning, T., Begemann, B., Mutschke, H., Dorschner, J., 1995. Optical properties of oxide dust grains. Astron. Astrophys. Suppl. 112 (112), 143-149.

Hervig, M., Thompson, R.E., McHugh, M., Gordley, L.L., Russell, J.M., Summers, M.E., 2001. First confirmation that water ice is the primary component of polar mesospheric clouds. Geophys. Res. Lett. 28 (6), 971-974, http://dx.doi.org/ 10.1029/2000GL012104.

Hervig, M.E., Gordley, L.L., 2010. Temperature, shape, and phase of mesospheric ice from solar occultation for ice experiment observations. J. Geophys. Res. 115 (D15), 208, http://dx.doi.org/10.1029/2010JD013918.

Hervig, M.E., Rapp, M., Latteck, R., Gordley, L.L., 2011. Observations of mesospheric ice particles from the ALWIN radar and SOFIE. J. Atmos. Sol.-Terr. Phys. 73 (14-15) 2176-2183, http://dx.doi.org/10.1016/j.jastp.2010.08.002.

Hervig, M.E., Deaver, L.E., Bardeen, C.G., Russell, J.M., Bailey, S.M., Gordley, L.L., 2012. The content and composition of meteoric smoke in mesospheric ice particles from SOFIE observations. J. Atmos. Sol.-Terr. Phys. 84-85, 1-6, http://dx.doi.org/ 10.1016/j.jastp.2012.04.005.

Hoppe, U.-P., Hall, C., Rottger, J., 1988. First observations of summer polar mesospheric backscatter with a $224 \mathrm{MHz}$ radar. Geophys. Res. Lett. 15 (1), 28.

Hunten, D.M., Turco, R.P., Toon, O.B., 1980. Smoke and dust particles of meteoric origin in the mesosphere and stratosphere. J. Atmos. Sci. 37 (6), 1342-1357.

Jaeger, C., Mutschke, H., Begemann, B., Dorschner, J., Henning, T., 1994. Steps toward interstellar silicate mineralogy. I. Laboratory results of a silicate glass of mean cosmic composition. Astron. Astrophys. Suppl. 292 (2).

Jensen, E., Thomas, G.E., 1989. On the diurnal variation of noctilucent clouds. J. Geophys. Res. 94 (D12).

Jesse, O., 1896. Die Hohe der leuchtenden Nachtwolken. Astron. Nachr. 140 (11), 161-168, http://dx.doi.org/10.1002/asna.18961401102.

Keesee, R.G., 1989. Nucleation and particle formation in the upper atmosphere J. Geophys. Res. 94 (D12), 14683-14692.

Lazzati, D., 2008. Non-local thermodynamic equilibrium dust nucleation in subsaturated vapours. Mon. Not. R. Astron. Soc. 384 (1), 165-172, http://dx.doi.org/ 10.1111/j.1365-2966.2007.12678.x.

Lübken, F.-J., Lautenbach, J., Hoffner, J., Rapp, M., Zecha, M., 2009. First continuous temperature measurements within polar mesosphere summer echoes. J. Atmos. Sol.-Terr. Phys. 71 (3-4), 453-463, http://dx.doi.org/10.1016/j.jastp.2008.06.001.

Lübken, F.-J., et al., 1990. Mean state densities, temperatures and winds during the MAC/SINE and MAC/EPSILON campaigns. J. Atmos. Terr. Phys. 52 (10-11), 955-970.

Megner, L., Gumbel, J., Rapp, M., Siskind, D., 2008. Reduced meteoric smoke particle density at the summer pole-implications for mesospheric ice particle nucleation. Adv. Space Res. 41, 41-49, http://dx.doi.org/10.1016/j.asr.2007.09.006.
Meinen, J., Eritt, M., Habig, J.C., Leisner, T., 2012. Optical properties of free sub-10$\mathrm{nm}$ diameter $\mathrm{Fe}_{2} \mathrm{O}_{3}$ nanoparticles studied by broad-band cavity enhanced absorption spectroscopy BB-CEAS. Appl. Phys. B 108 (3), 641-647, http://dx. doi.org/10.1007/s00340-012-5044-3.

Murphy, D.M., Koop, T., 2005. Review of the vapour pressures of ice and supercooled water for atmospheric applications. Q. J. R. Meteorol. Soc. 131 (608), 1539-1565.

Murray, B.J., Jensen, E.J., 2010. Homogeneous nucleation of amorphous solid water particles in the upper mesosphere. J. Atmos. Sol.-Terr. Phys. 72 (1), 51-61.

Petelina, S.V., Zasetsky, A.Y., 2009. Temperature of mesospheric ice retrieved from the O-H stretch band. Geophys. Res. Lett. 36 (L15), 804, http://dx.doi.org/ 10.1029/2009GL038488.

Pound, G.M., Simnad, M.T., Yang, L., 1954. Heterogeneous nucleation of crystals from vapor. J. Chem. Phys. 22 (7), 1215-1219.

Pruppacher, H.R., Klett, J.D., 1997. Microphysics of Clouds and Precipitation, 2nd ed. Kluwer Academic Publishers, Dordrecht, Boston.

Rapp, M., 2002. Small-scale temperature variations in the vicinity of NLC: experimental and model results. J. Geophys. Res. 107 (D19), http://dx.doi.org/10.1029/ 2001JD001241.

Rapp, M., Lübken, F.-J., 2004. Polar mesosphere summer echoes (PMSE): review of observations and current understanding. Atmos. Chem. Phys. 4 (11/12), 2601-2633.

Rapp, M., Thomas, G.E., 2006. Modeling the microphysics of mesospheric ice particles: assessment of current capabilities and basic sensitivities. J. Atmos. Sol.-Terr. Phys. 68 (7), 715-744.

Rottger, J., La Hoz, C., Kelley, M.C., Hoppe, U.-P., Hall, C., 1988. The structure and dynamics of polar mesosphere summer echoes observed with the EISCAT $224 \mathrm{MHz}$ radar. Geophys. Res. Lett. 15 (12), 1353.

Saunders, R.W., et al., 2010. An aerosol chamber investigation of the heterogeneous ice nucleating potential of refractory nanoparticles. Atmos. Chem. Phys. 10 (3), 1227-1247.

Seki, J., Hasegawa, H., 1983. The heterogeneous condensation of interstellar ice grains. Astrophys. Space Sci. 94 (1), 177-189.

Sigsbee, R.A., 1969. Vapor to condensed-phase heterogeneous nucleation. In: Zettlemoyer, A.C. (Ed.), Nucleation. Marcel Dekker, New York, pp. 151-224.

Sugiyama, T., 1996. Oscillations in polar mesospheric summer echoes and bifurcation of noctilucent cloud formation. Geophys. Res. Lett. 23 (6), 653-656.

Thomas, G.E., 1991. Mesospheric clouds and the physics of the mesopause region. Rev. Geophys. 29 (4), 553, http://dx.doi.org/10.1029/91RG01604.

Toon, O.B., Turco, R.P., Hamill, P., Kiang, C.S., Whitten, R.C., 1979. A one-dimensional model describing aerosol formation and evolution in the stratosphere. II. Sensitivity studies and comparison with observations. J. Atmos. Sci. 36 (4), 718-736, http://dx.doi.org/10.1175/1520-0469(1979)036 < 0718:AODMDA > 2.0.CO;2.

Toon, O.B., Turco, R.P., Westphal, D., Malone, R., Liu, M., 1988. A multidimensional model for aerosols: description of computational analogs. J. Atmos. Sci. 45 (15), 2123-2143, http://dx.doi.org/10.1175/1520-0469(1988)045 < 2123:AMMFAD > 2.0.CO;2.

Turco, R.P., Hamill, P., Toon, O.B., Whitten, R.C., Kiang, C.S., 1979. A one-dimensional model describing aerosol formation and evolution in the stratosphere. I. Physical processes and mathematical analogs. J. Atmos. Sci. 36 (4), 699-717, http://dx.doi.org/10.1175/1520-0469(1979)036 < 0699:AODMDA > 2.0.CO;2.

Turco, R.P., Toon, O.B., Whitten, R.C., Keesee, R.G., Hollenbach, D., 1982. Noctilucent clouds: simulation studies of their genesis, properties and global influences. Planet. Sp. Sci. 30 (11), 1147-1181, http://dx.doi.org/10.1016/0032-0633(82) 90126-X.

van de Hulst, H.C., 1981. Light Scattering by Small Particles. Dover Publications, New York.

Warren, S.G., Brandt, R.E., 2008. Optical constants of ice from the ultraviolet to the microwave: a revised compilation. J. Geophys. Res. 113 (D14), D14,220, http: //dx.doi.org/ 10.1029/2007JD009744.

Witt, G., 1969. The nature of noctilucent clouds. Space Res. 9 (IX), 157-169.

Zeidler, S., Posch, T., Mutschke, H., Richter, H., Wehrhan, O., 2011. Near-infrared absorption properties of oxygen-rich stardust analogs. Astron. Astrophys. 526, A68. 